\title{
Trait-Abundance Relationships of Annual Ephemerals in Response to Nitrogen Addition in Gurbantunggut Desert
}

\author{
Mao Wang, Haiyang Ma (D) and Dunyan Tan * \\ College of Life Sciences, Xinjiang Agricultural University, Ürümqi 830052, China; wangmao@xjau.edu.cn (M.W.); \\ 17719312529@163.com (H.M.) \\ * Correspondence: tandunyan@163.com
}

check for updates

Citation: Wang, M.; Ma, H.; Tan, D. Trait-Abundance Relationships of Annual Ephemerals in Response to Nitrogen Addition in Gurbantunggut Desert. Diversity 2021, 13, 569. https://doi.org/10.3390/d13110569

Academic Editors: Qinglai Dang and Mario A. Pagnotta

Received: 11 September 2021

Accepted: 5 November 2021

Published: 7 November 2021

Publisher's Note: MDPI stays neutral with regard to jurisdictional claims in published maps and institutional affiliations.

Copyright: (c) 2021 by the authors. Licensee MDPI, Basel, Switzerland. This article is an open access article distributed under the terms and conditions of the Creative Commons Attribution (CC BY) license (https:/ / creativecommons.org/licenses/by/ $4.0 /)$.

\begin{abstract}
Understanding the effect of nitrogen addition on species trait-abundance relationships is one of the central focuses of community ecology and can offer us insights into the mechanisms of community assembly under atmospheric nitrogen deposition. However, few studies have focused on desert ecosystems. In this study, we measured the abundance and ecological stoichiometric traits, leaf carbon content (LCC), nitrogen content (LNC), and phosphorus content (LPC) for all annual ephemerals in all plots subjected to nitrogen addition in early spring in Gurbantunggut Desert, northern Xinjiang, China. We found a significant relationship between traits (LNC, N:P, and C:N) and abundance, indicating that ecological stoichiometry is a good proxy for explaining and predicting species abundance. We further found that significant trait-abundance relationships still existed under different nitrogen addition levels. The result suggests that trait-based niche-assembly theory plays an important role in determining species abundance under atmospheric nitrogen deposition.
\end{abstract}

Keywords: community assembly; abundance; ecological stoichiometric traits; annual ephemeral; desert

\section{Introduction}

Understanding why some species are abundant and others are rare in a given site is one of the central foci of community ecology [1-3]. Mechanisms influencing the abundance of species in a community are a subject of ongoing debate. Trait-based niche-assembly theory demonstrates that environmental filtering and limiting similarity act as a set of filters for local community assembly [4-6]; those filtering processes determine which species (according to their trait values) have a greater probability of being present and becoming dominant under specific environmental conditions [7-10]. If this is true, species traits and abundance will be linked to communities. However, the neutral theory of community assembly holds that limited dispersal in space and stochastic processes create realistic distributions of species in certain conditions [11]. By this theory, species are essentially ecologically equivalent, independently of their traits; therefore, there will be no correlation between species abundance and traits within communities.

Many studies have examined trait-abundance relationships in different types of communities, and the results were complicated and controversial [12-15]. Although much research has supported niche theory, not all traits are related to abundance [13]. The traits related to competitive performance, such as growth rate, specific leaf area, leaf nitrogen concentration, and photosynthetic rate, may be more strongly correlated with abundance $[10,16,17]$. However, it has still been reported that traits unrelated to competitiveness correlate with abundance $[10,18]$. Thus, it is still very important to analyze which types of traits are related to abundance.

Besides this, examining the relationship between traits and abundance within a single environment is not enough to conclude which species traits determine abundance. The general view is that environmental conditions drive optimal trait combinations, which can affect species abundance $[19,20]$; therefore, changes in environmental factors can lead to shifts in the given trait-abundance relationships (not only a shift in the slope but given 
trait-abundance relationships can also appear or disappear) [10,17]. For example, a study in a Tibetan alpine meadow community showed that a significant correlation between leaf dry matter content (LDMC) and abundance appeared [21] while the significant correlation between specific leaf area (SLA) and abundance disappeared under long-term phosphate addition [22]. Thus, it is essential to test whether the specific trait-abundance relationships still exist under different environmental conditions.

Nitrogen deposition has become one of the most important environmental changes in the world; it can influence soil nutrient availability and thus affect the species distribution $[23,24]$. It is generally accepted that species with traits related to rapid resource acquisition become dominant under added soil resources, whereas those related to resource conservation have superiority under lower soil resource availability [25]. The relationships between traits and abundance may vary because they mirror different aspects of species performance under changing conditions $[22,26,27]$. However, how nitrogen addition affects the relationships between traits and abundance remains uncertain, especially in desert ecosystems.

Annual ephemerals are not only an important component of the plant community in early spring in Gurbantunggut Desert, northern Xinjiang, but they are also the main herbaceous plant groups that are significantly different from those in other deserts in China [28]. Although the life history of annual ephemerals in the study area is not long-about 75 days, germinating at the end of March when snow melts and finishing in May or June when the hot and dry summer comes in - the coverage can reach more than $50 \%$ in May due to the large number and the formation of obvious herb layers. Therefore, annual ephemerals in early spring are important for reducing the flow of sand and stabilizing the sand surface in Gurbantunggut Desert in northern Xinjiang. To test the relationships between the traits and abundance of annual ephemerals, we measured the relative abundance and ecological stoichiometric traits, leaf carbon content (LCC), nitrogen content (LNC), and phosphorus content (LPC), which are among the most important limiting nutrients in terrestrial ecosystems and play vital roles in the photosynthetic and metabolic processes, growth, and productivity of plants [29-31], for six common species in each plot of a nitrogen addition experiment. In this study, we aim to address the following scientific questions: (1) Can one or some combination of ecological stoichiometric traits explain species abundance? Further, (2) do different levels of nitrogen addition lead to changes in the relationships between trait and abundance?

\section{Methods}

\subsection{Study Site}

This experiment was conducted in the northern portion of the Gurbantunggut Desert, northern Xinjiang, China $\left(44^{\circ} 33^{\prime} \mathrm{N}, 88^{\circ} 16^{\prime} \mathrm{E}\right.$, altitude $525 \mathrm{~m}$ a.s.l) (Figure 1). This region belongs to the typical continental arid and semi-arid desert climate with a hot summer and cold winter. The mean annual temperature is $7.1{ }^{\circ} \mathrm{C}$, the extreme maximum temperature in summer is $42.6{ }^{\circ} \mathrm{C}$, and the extreme minimum temperature in winter is $-41.6{ }^{\circ} \mathrm{C}$. The mean annual precipitation is $215.6 \mathrm{~mm}$, while the potential evaporation is about $2000 \mathrm{~mm}$. The soil is grey desert soil with low fertility [32]. The local vegetation at the site is dominated by Haloxylon ammodendron and H. persicum. Herbaceous plants include annual ephemerals, annual plants, and perennial plants. Annual ephemerals in this area have a short life history-about 75 days, germinating at the end of March when snow melts and finishing in May or June when the hot and dry summer comes in. In particular, with significantly greater biomass (more than $80 \%$ ) and coverage (more than $50 \%$ ) than other herbs in May, annual ephemerals are the main constructors of the early spring plant community in this area [33]. At this study site, the common annual ephemerals are Alyssum linifolium, Erodium oxyrrhynchum, Trigonella arcuate, Eremopyrum distans, Lappula semiglabra, and Hyalea pulchella (Table S1). 


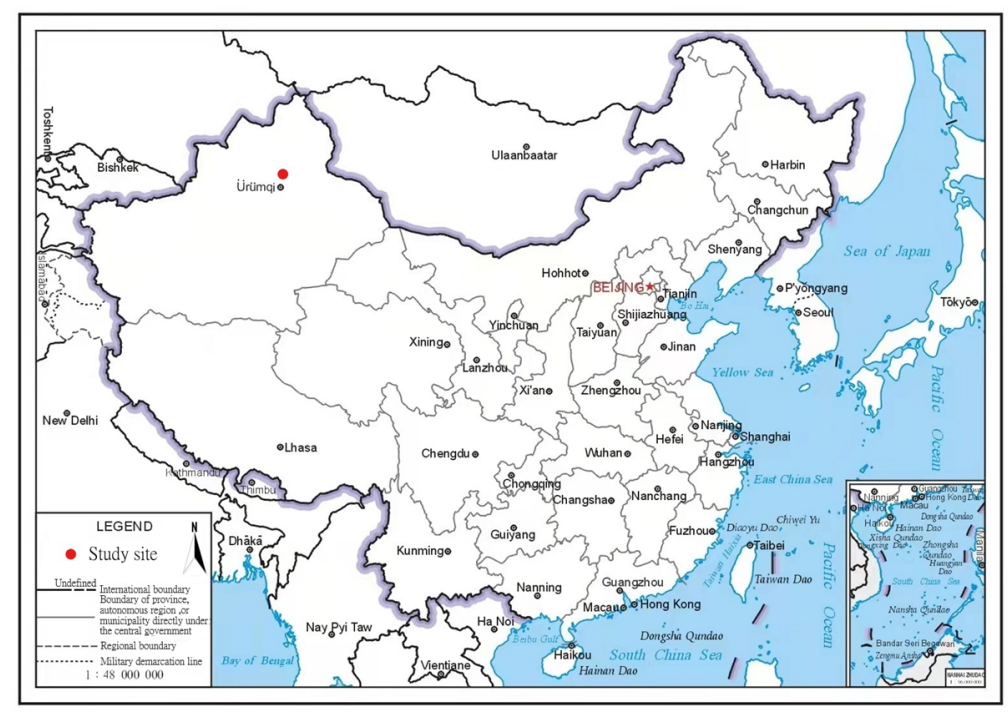

Figure 1. Geographical location of the study site.

\subsection{Experimental Design}

A nitrogen addition experiment was established in 2018 on a flat area that was fenced to prevent grazing by camels. A total of 16 plots of size $2 \times 2 \mathrm{~m}^{2}$, each separated by $0.5 \mathrm{~m}$, were randomly allocated to control, low, medium, and high nitrogen addition treatments (CK: $0 \mathrm{~g} / \mathrm{m}^{2}, \mathrm{~N} 1$ (low): $3 \mathrm{~g} / \mathrm{m}^{2}, \mathrm{~N} 2$ (medium): $6 \mathrm{~g} / \mathrm{m}^{2}, \mathrm{~N} 3$ (high): $12 \mathrm{~g} / \mathrm{m}^{2}$, respectively). Each of these four treatments was replicated four times. At the end of March, when the snow had melted, we sprayed the nitrogen evenly on the plots according to the addition levels. The control plots were sprayed with the same amount of water to reduce the impact caused by the additional water.

\subsection{Species Abundance and Ecological Stoichiometric Measurements}

In 2019, species abundance was calculated in mid-May when the number of each species found in the plots reached a maximum. For each species in all plots, we randomly selected five individuals and sampled six mature undamaged leaves from each individual. In total, 30 mature undamaged leaves were collected for each species. Fresh leaves were oven dried at $80{ }^{\circ} \mathrm{C}$ for $72 \mathrm{~h}$ and ground into a fine powder to measure the ecological stoichiometry. The leaf carbon and nitrogen contents were measured by dry combustion with an elemental analyzer (Euro Vector EA3000, Milan, IT). For the leaf phosphorus content, $50 \mathrm{mg}$ of sample was digested in $1 \mathrm{~mL}$ of a $1: 4$ mixture of $37 \%(v / v) \mathrm{HCl}$ and $65 \%(v / v) \mathrm{HNO}_{3}$ in a closed Teflon cylinder for $6 \mathrm{~h}$ at $140{ }^{\circ} \mathrm{C}$. Samples were then diluted with $4 \mathrm{~mL}$ demineralized water, and the total leaf phosphorus content was quantified by spectrophotometry using the ammonium molybdate method [34].

\subsection{Data Analysis}

In each plot, we calculated the relative abundance as the number of individuals of a given species divided by the total number of individuals of all species. We calculated the means of ecological stoichiometric traits (LCN, LNC, LPC, C:N, N:P, and C:P) for each species in all plots. The effects of nitrogen addition on plot abundance and species relative abundance were tested by one-way ANOVA. To evaluate the trait-abundance relationship, we standardized the data via log transform. A general linear regression model was used to evaluate the relationship between the ecological stoichiometric traits and relative abundance of species in each treatment. All statistical analyses were performed with R [35] software and SigmaPlot 10.0 software. 


\section{Results}

Although the responses of relative abundance of each species to nitrogen addition were not significant, the abundance in plots tended to decrease with an increase in nitrogen addition (Figure S1, Table S2). The responses of ecological stoichiometry to nitrogen addition depended on species attributes. Overall, the leaf nitrogen content of species tended to increase following nitrogen addition (Table S3).

Irrespective of nitrogen addition, we found that the relative abundance of species was positively correlated with $\mathrm{LNC}\left(R^{2}=0.71, p<0.01\right)$ and N:P $\left(R^{2}=0.73, p<0.01\right)$ but negatively correlated with $\mathrm{C}: \mathrm{N}\left(R^{2}=0.64, p<0.01\right)$ (Figure 2). There was a weak positive correlation between the relative abundance and C:P $\left(R^{2}=0.17, p=0.04\right)$. When nitrogen addition was considered, the abovementioned significant relationships between traits and abundance still existed in the control and treatment plots, except that of C:P (Figure 3).
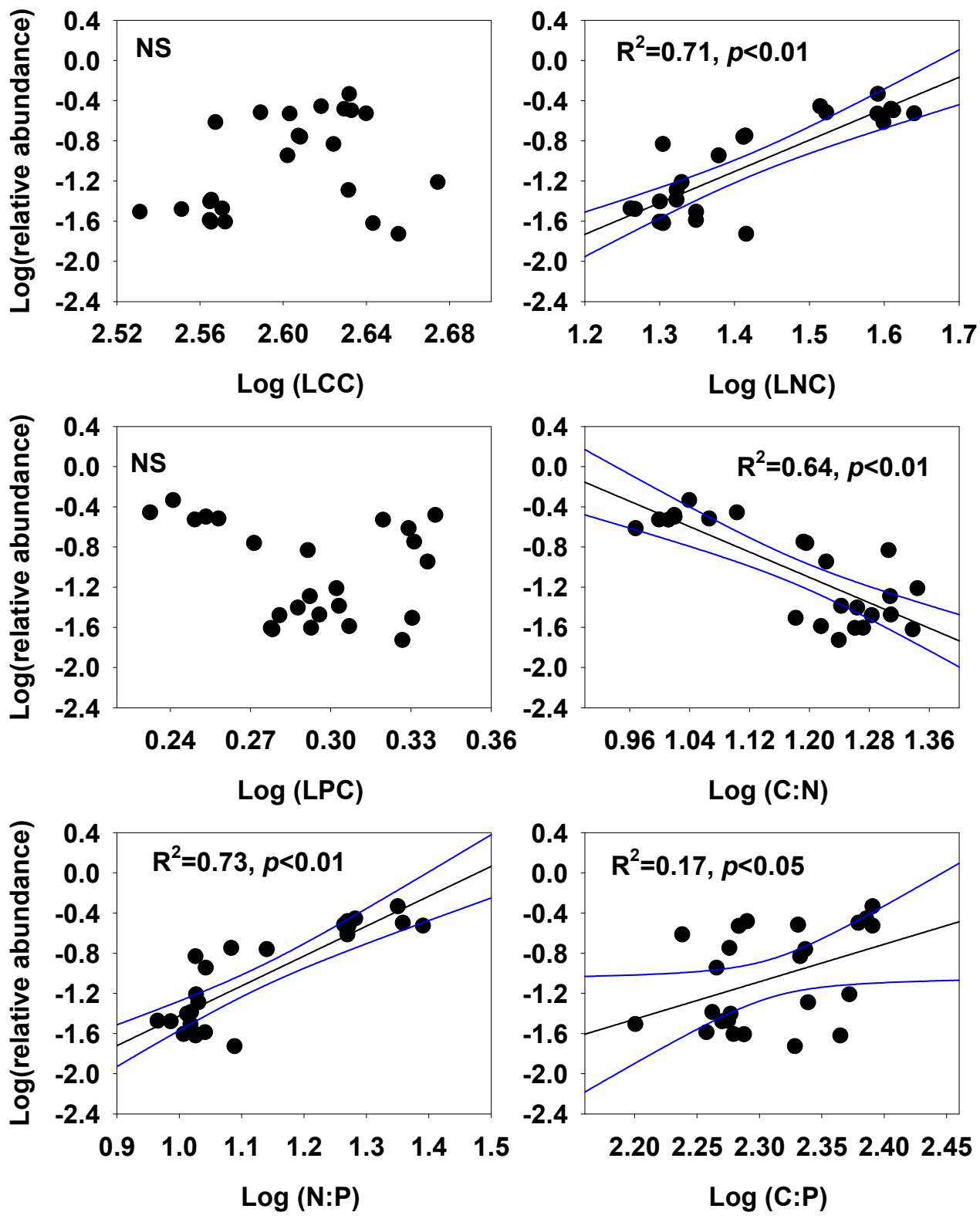

Figure 2. Relationships between species' relative abundance and ecological stoichiometric traits among common species in all plots, irrespective of nitrogen addition. LCC, leaf carbon content; LNC, leaf nitrogen content; LPC, leaf phosphorus content. 

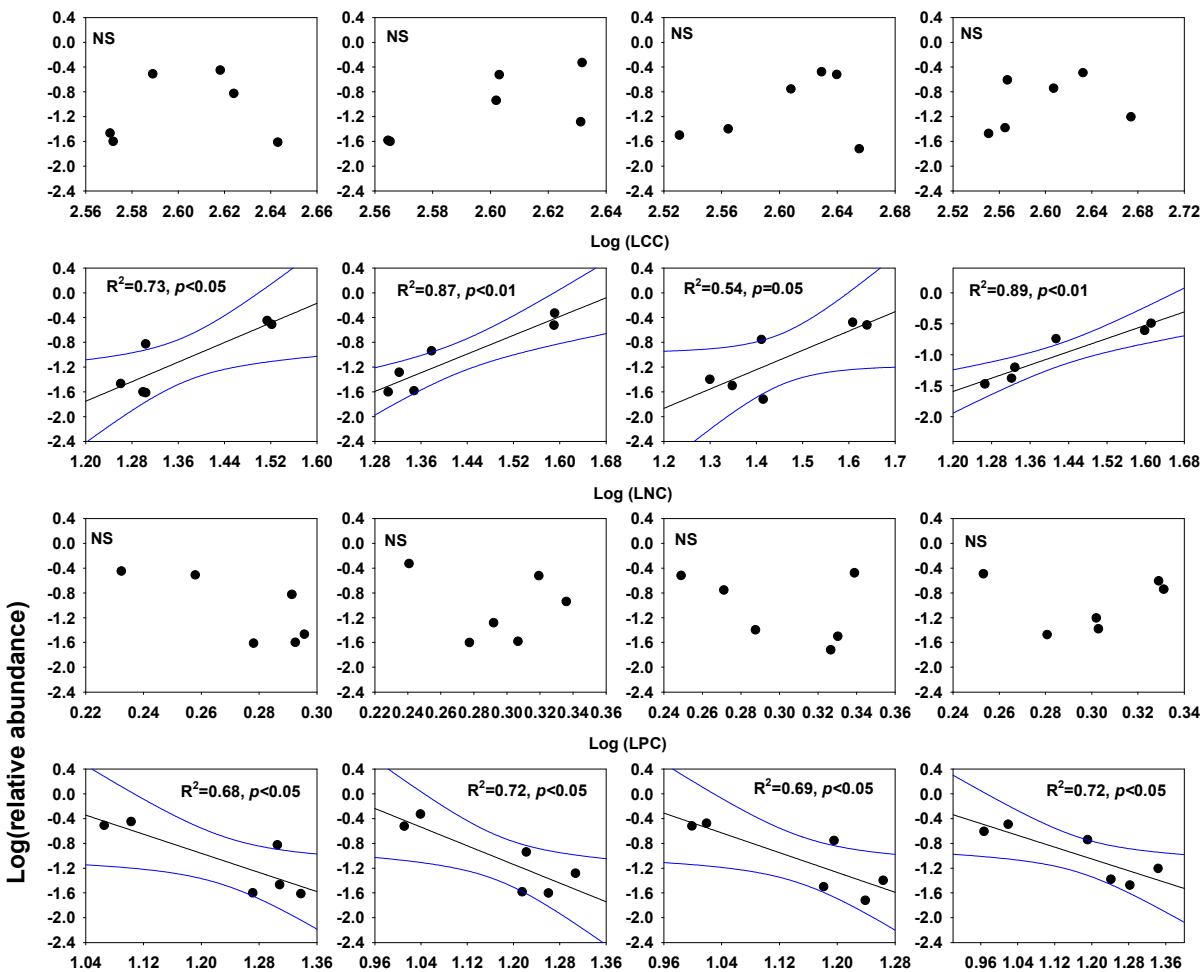
$\log (\mathrm{LNC})$

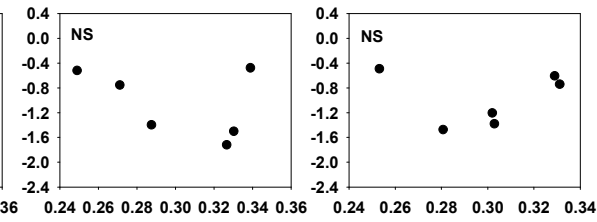

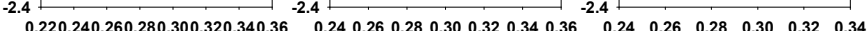
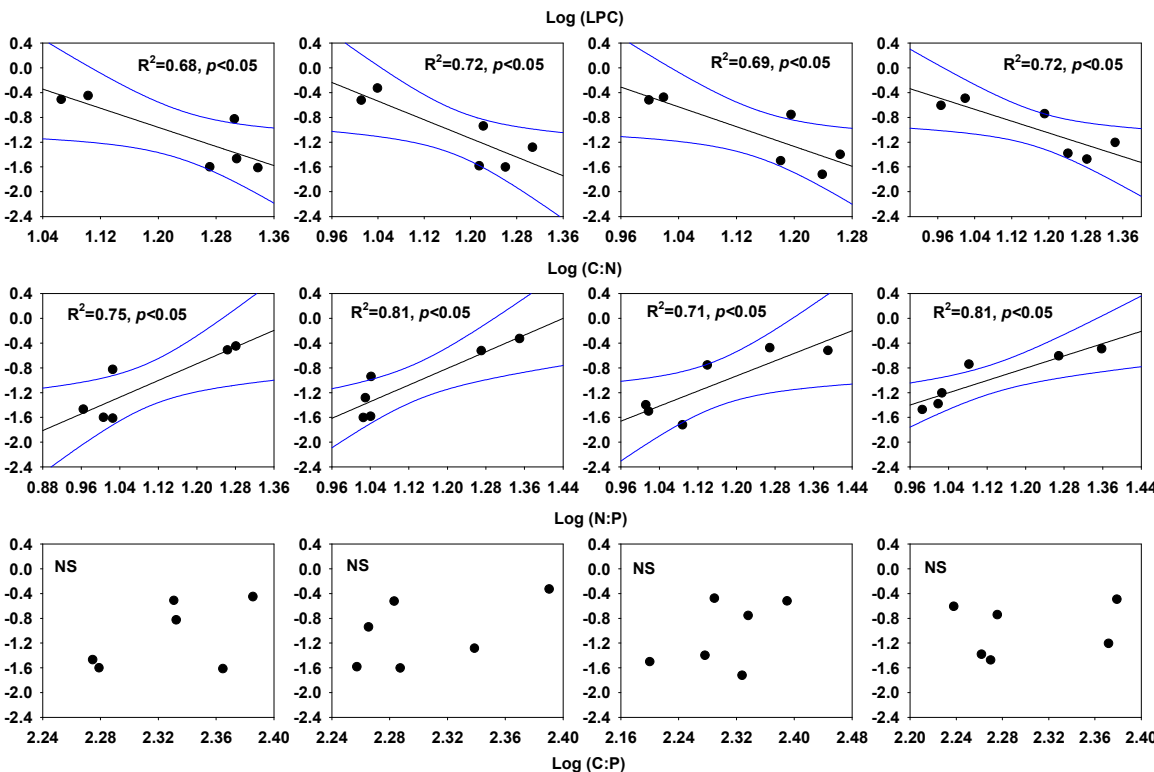

$\log (\mathrm{N}: \mathrm{P})$

No

N1

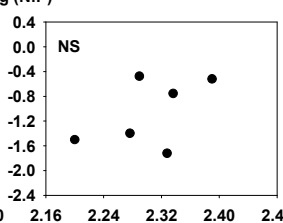
$\operatorname{og}(\mathrm{C}: \mathrm{P})$

N2

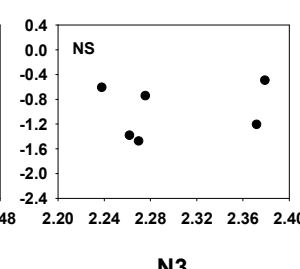

N3

Figure 3. Relationships between species' relative abundance and ecological stoichiometric traits among common species in the control and nitrogen addition plots. N0, N1, N2, and N3 indicate nitrogen addition amounts of $0,3,6$, and $12 \mathrm{~g} / \mathrm{m}^{2}$, respectively.

\section{Discussion}

\subsection{Which Ecological Stoichiometric Traits Explain Species Abundance?}

We found significant relationships between ecological stoichiometric traits (LNC, N:P, and $\mathrm{C}: \mathrm{N}$ ) and species' relative abundance, supporting the idea that traits affect species abundance $[8,12,15]$. In this study, LNC was positively associated with relative abundance. LNC is a key trait associated with competitive strategy as it is integral to all enzymatic activity, especially rubisco, a component of photosynthetic machinery [36]. Consequently, species with higher leaf nitrogen content usually have a stronger photosynthetic capacity and faster growth rate than others, thus holding an advantageous position in competition and becoming dominant in the community [37-39]. As fast-growing and "opportunistic" species, annual ephemerals with high soil seed bank capacity can germinate explosively after snow melting, grow quickly, produce copious seeds, and die within a few weeks in the study area $[28,40]$. Given the specific life history strategy of annual ephemerals, it would be surprising if leaf $\mathrm{N}$ did not affect species abundance. 
Interestingly, although in other systems there is often a significant relationship between leaf carbon and abundance [22,41], we found no evidence for it in the annual ephemerals of Gurbantunggut Desert. Leaf carbon content is usually considered a structural trait related to resource conservation and stress-tolerance strategy [42,43]. However, traits that favor rapid plant growth are expected to have an important influence on species abundance [17]. Obviously, the fast-growth strategy adopted by annual ephemerals as "opportunists" may decouple the traits of leaf carbon and abundance. Although leaf phosphorus has specific functions in protein synthesis, we also found no relationship between leaf phosphorus and abundance. It is generally known that nitrogen is the most deficient nutrient in the soil of Gurbantunggut Desert [32]. As plants are generally coupled with soil nutrition [44], the leaf stoichiometric traits mirror the ability of plants to obtain limited nutrients (nitrogen rather than phosphorus) in determining the abundance of plants in this area.

Stoichiometric ratios apparently play a major role in the biochemistry of physiology and performance in most organisms [45]. In this study, we found that the relative abundance of annual ephemerals was positively correlated with $\mathrm{N}: \mathrm{P}\left(R^{2}=0.73, p<0.01\right)$. Given the biochemistry and function of N-rich proteins and P-rich RNA, leaf N:P can reflect the plant growth rate [46]. High leaf N:P means more efficient uptake of $\mathrm{N}$ when unit phosphorus is absorbed. Leaf C:N represents the ratio of plant photosynthetic $\mathrm{C}$ and root $\mathrm{N}$ uptake, while leaf $\mathrm{N}$ regulates rates of $\mathrm{C}$ acquisition and use. A negative relationship between $\mathrm{C}: \mathrm{N}$ and relative abundance of annual ephemerals indicates that high $\mathrm{N}$ use efficiency can promote plant photosynthesis, thereby making them dominant in the community.

\subsection{Relationships between Species Relative Abundance and Ecological Stoichiometry with Nitrogen Addition}

We found that the ecological stoichiometric traits of a given species are a strong predictor of its abundance, and this relationship still exists under different nitrogen addition amounts. Our results are seemingly inconsistent with previous studies that concluded that trait-abundance relationships are dependent on the environmental context $[10,13,17]$. There are two main reasons for this that we would like to highlight in this section. First, the core and essence of trait-abundance relationships is dependent on the environment, which changes to dominant species with different life history strategies in or among communities. For example, plants adapted to tolerance strategies benefit more from nutrient-poor habitats, while fertile habitats tend to favor plants with rapid growth strategies [36,47]. As mentioned above, all annual ephemerals adopt the rapid growth strategy in order to avoid the heat and drought of summer. This single life history strategy of annual ephemerals may lead to trait-abundance relationships still existing whether in nutrient-poor or fertile habitats in early spring in Gurbantunggut Desert.

Second, previous studies concerning the effect of nitrogen addition on trait-abundance relationships generally focused on perennials and were conducted over a long time [22,25,48]. The main reasons for this are that perennials have a long life span (two or more years), and atmospheric nitrogen deposition affecting plant species abundance through favoring species better adapted to high nutrient levels will take a long time. In this study, based on the short life history (about 75 days) of annual ephemerals, we conducted a two-year nitrogen addition experiment and demonstrated that trait-abundance relationships still existed under short-term nitrogen addition. However, long-term atmospheric nitrogen deposition can change many soil properties, such as physical, chemical, and biological properties [49,50], and will finally influence the seed bank and seed germination in soil [51,52]. All these factors have potential importance to the trait-abundance relationships of species. Thus, a long-term nitrogen addition experiments should be considered in future work in order to provide a more comprehensive understanding of trait-abundance relationships in the annual ephemeral layer.

Overall, our results of significant trait-abundance relationships were unchanged under different nitrogen addition levels, suggesting that trait-based niche-assembly theory plays an important role in determining species abundance under atmospheric nitrogen deposition $[13,15]$. The type of life history strategy of research objects should be included when 
trait-abundance relationships dependent on the environment are examined, especially under atmospheric nitrogen deposition.

\section{Conclusions}

In conclusion, significant relationships between traits (LNC, N:P, and C:N) and abundance were established within the annual ephemeral layer of the early spring plant community of Gurbantunggut Desert, China, which suggests that these traits can affect species abundance and highlights that ecological stoichiometry is a good proxy for explaining and predicting species abundance. Although the significant trait-abundance relationships were present under different nitrogen addition levels, suggesting that trait-based niche-assembly theory plays an important role in determining species abundance, a long-term nitrogen addition experiment should be considered in future work in order to provide a more comprehensive understanding of trait-abundance relationships in the annual ephemeral layer.

Supplementary Materials: The following are available online at https:/ /www.mdpi.com/article/10 $.3390 / d 13110569 /$ s1. Figure S1: Variation in the abundance of the annual ephemeral layer under different nitrogen addition levels (mean \pm SD), Table S1: Information on the six most common annual ephemerals at the study site, Table S2: The responses in the relative abundance of each species to nitrogen addition (mean \pm SD), Table S3: The responses in the stoichiometric traits of each species to ni-trogen addition (mean $\pm \mathrm{SD}$ ).

Author Contributions: Conceptualization, M.W. and D.T.; methodology, M.W.; software, M.W.; validation, M.W., D.T. and H.M.; formal analysis, M.W.; investigation, M.W. and H.M.; resources, M.W.; data curation, M.W.; writing—original draft preparation, M.W.; writing—review and editing, M.W. and H.M.; visualization, M.W.; supervision, D.T.; project administration, D.T.; funding acquisition, M.W. All authors have read and agreed to the published version of the manuscript.

Funding: This research was funded by the Grassology Peak Discipline Foundation of Xinjiang Uygur Autonomous Region, China (CXGFXK-2017-03), National Natural Science Foundation of China (31960260, 32071668), Tianshan Youth Program of Xinjiang Uygur Autonomous Region (2019Q078), and Natural Science Foundation of Xinjiang Uygur Autonomous Region (2018D01B23). The APC was funded by the Grassology Peak Discipline Foundation of Xinjiang Uygur Autonomous Region, China.

Institutional Review Board Statement: Not applicable.

Informed Consent Statement: Not applicable.

Data Availability Statement: The processed data required to reproduce these findings cannot be shared at this time as the data also forms part of an ongoing study.

Acknowledgments: We wish to thank our colleagues for their help. A special thanks to Fengyi Lei and Shuyuan Fan for field work. We are grateful to two reviewers for their constructive comments, which helped us to improve the manuscript.

Conflicts of Interest: The authors declare no conflict of interest.

\section{References}

1. Preston, F.W. The commonness, and rarity, of species. Ecology 1948, 29, 254-283. [CrossRef]

2. McGill, B.J.; Enquist, B.J.; Weiher, E.; Westoby, M. Rebuilding community ecology from functional traits. Trends Ecol. Evol. 2006, 21, 178-185. [CrossRef] [PubMed]

3. Umaña, M.N.; Zhang, C.; Cao, M.; Lin, L.; Swenson, N.G. Commonness, rarity, and intraspecific variation in traits and performance in tropical tree seedlings. Ecol. Lett. 2015, 18, 1329-1337. [CrossRef]

4. Díaz, S.; Cabido, M.; Casanoves, F. Plant functional traits and environmental filters at a regional scale. J. Veg. Sci. 1998, 9, 113-122. [CrossRef]

5. Weiher, E.; Keddy, P.A. The assembly of experimental wetland plant communities. Oikos 1995, 73, 323-335. [CrossRef]

6. Wang, M.; Xu, J.; Chai, Y.; Guo, Y.; Liu, X.; Yue, M. Differentiation of environmental conditions promotes variation of two Quercus wutaishanica community assembly patterns. Forests 2020, 11, 43. [CrossRef]

7. Keddy, P.A. Assembly and response rules: Two goals for predictive community ecology. J. Veg. Sci. 1992, 3, 157-164. [CrossRef]

8. Kraft, N.J.; Valencia, R.; Ackerly, D.D. Functional traits and niche-based tree community assembly in an Amazonian forest. Science 2008, 322, 580-582. [CrossRef] 
9. Wang, M.; Wan, P.; Chai, Y.; Guo, Y.; Zhang, X.; Yue, M. Adaptative strategy of leaf traits to drought conditions: Quercus aliena var. acuteserrata forest (The Qinling Mts. China). Pol. J. Ecol. 2015, 63, 77-87.

10. Zhang, H.; John, R.; Zhu, S.; Liu, H.; Xu, Q.; Qi, W.; Liu, K.; Ye, Q. Shifts in functional trait-species abundance relationships over secondary subalpine meadow succession in the Qinghai-Tibetan Plateau. Oecologia 2018, 188, 547-557. [CrossRef]

11. Hubbell, S.P. Neutral theory in community ecology and the hypothesis of functional equivalence. Funct. Ecol. 2005, 19, 166-172. [CrossRef]

12. Suding, K.N.; Goldberg, D.E.; Hartman, K.M. Relationships among species traits: Separating levels of response and identifying linkages to abundance. Ecology 2003, 84, 1-16. [CrossRef]

13. Cornwell, W.K.; Ackerly, D.D. A link between plant traits and abundance: Evidence from coastal California woody plants. J. Ecol. 2010, 98, 814-821. [CrossRef]

14. Brenes-Arguedas, T.; Roddy, A.B.; Kursar, T.A. Plant traits in relation to the performance and distribution of woody species in wet and dry tropical forest types in Panama. Funct. Ecol. 2013, 27, 392-402. [CrossRef]

15. Loranger, J.; Munoz, F.; Shipley, B.; Violle, C. What makes trait-abundance relationships when both environmental filtering and stochastic neutral dynamics are at play? Oikos 2018, 127, 1735-1745. [CrossRef]

16. Harpole, W.S.; Tilman, D. Non-neutral patterns of species abundance in grassland communities. Ecol. Lett. 2006, 9, 15-23.

17. Yan, E.; Yang, X.; Chang, S.; Wang, X. Plant trait-species abundance relationships vary with environmental properties in subtropical forests in Eastern China. PLoS ONE 2013, 8, e61113. [CrossRef] [PubMed]

18. Reader, R.J. Relationship between species relative abundance and plant traits for an infertile habitat. Plant. Ecol. 1998, 134, 43-51. [CrossRef]

19. Niu, K.; Zhang, S.; Zhao, B.; Du, G. Linking grazing response of species abundance to functional traits in the Tibetan alpine meadow. Plant. Soil. 2010, 330, 215-223. [CrossRef]

20. Bruelheide, H.; Dengler, J.; Purschke, O.; Lenoir, J.; Jiménez-Alfaro, B.; Hennekens, S.M.; Botta-Dukát, Z.; Chytrý, M.; Field, R.; Jansen, F.; et al. Global trait-environment relationships of plant communities. Nat. Ecol. Evol. 2018, 2, 1906-1917. [CrossRef]

21. Zhou, X.; Wang, Y.; Zhang, P.; Guo, Z.; Chu, C.; Du, G. The effects of fertilization on the trait-abundance relationships in a Tibetan alpine meadow community. J. Plant Ecol. 2016, 9, 144-152. [CrossRef]

22. Liu, H.; Li, Y.; Ren, F.; Lin, L.; Zhu, W.; He, J.; Niu, K. Trait-abundance relation in response to nutrient addition in a Tibetan alpine meadow: The importance of species trade-off in resource conservation and acquisition. Ecol. Evol. 2017, 7, 10575-10581. [CrossRef] [PubMed]

23. Janssens, I.A.; Dieleman, W.; Luyssaert, S.; Subke, J.A.; Reichstein, M.; Ceulemans, R.; Ciais, P.; Dolman, A.J.; Grace, J.; Matteucci, G. Reduction of forest soil respiration in response to nitrogen deposition. Nat. Geosci. 2010, 3, 315-322. [CrossRef]

24. Franklin, J.; Serradiaz, J.M.; Syphard, A.D.; Syphard, A.D.; Regan, H.M. Global change and terrestrial plant community dynamics. Proc. Natl. Acad. Sci. USA 2016, 113, 3725-3734. [CrossRef] [PubMed]

25. Laliberté, E.; Shipley, B.; Norton, D.A.; Scott, D. Which plant traits determine abundance under long-term shifts in soil resource availability and grazing intensity? J. Ecol. 2012, 100, 662-677. [CrossRef]

26. Marks, C.O.; Lechowicz, M.J. Alternative designs and the evolution of functional diversity. Am. Nat. 2006, 167, 55-66. [CrossRef]

27. Reich, P.B. The world-wide 'fast-slow' plant economics spectrum: A traits manifesto. J. Ecol. 2014, 102, 275-301. [CrossRef]

28. Mao, Z.; Zhang, D. The conspectus of ephemeral flora in northern Xinjiang. Arid Zone Res. 1994, 3, 1-26, (In Chinese with English Abstract).

29. Chapin, F.S., III. The mineral nutrition of wild plants. Annu. Rev. Ecol. Syst. 1980, 11, 233-260. [CrossRef]

30. Han, W.; Fang, J.; Guo, D.; Zhang, Y. Leaf nitrogen and phosphorus stoichiometry across 753 terrestrial plant species in China. New phytol. 2005, 168, 377-385. [CrossRef] [PubMed]

31. Zechmeister-Boltenstern, S.; Keiblinger, K.M.; Mooshammer, M.; Peñuelas, J.; Richter, A.; Sardans, J.; Wanek, W. The application of ecological stoichiometry to plant-microbial-soil organic matter transformations. Ecol. Monogr. 2015, 85, 133-155. [CrossRef]

32. Cui, X.; Yue, P.; Gong, Y.; Li, K.; Tan, D.; Goulding, K.; Liu, X. Impacts of water and nitrogen addition on nitrogen recovery in Haloxylon ammodendron dominated desert ecosystems. Sci. Total. Environ. 2017, 601, 1280-1288. [CrossRef]

33. Huang, G.; Su, Y.; Zhu, L.; Li, Y. The role of spring ephemerals and soil microbes in soil nutrient retention in a temperate desert. Plant. Soil. 2016, 406, 43-54. [CrossRef]

34. Murphy, J.; Riley, J.P. A modifed single solution method for the determination of phosphate in natural waters. Anal. Chim. Acta. 1962, 27, 31-36. [CrossRef]

35. R Development Core Team. R: A Language and Environment for Statistical Computing; R Foundation for Statistical Computing: Vienna, Austria, 2021.

36. Wright, I.J.; Reich, P.B.; Westoby, M.; Ackerly, D.D.; Baruch, Z.; Bongers, F.; Cavender-Bares, J.; Chapin, T.; Cornelissen, J.H.; Diemer, M.; et al. The worldwide leaf economics spectrum. Nature 2004, 428, 821-827. [CrossRef] [PubMed]

37. Evans, J.R. Photosynthesis and nitrogen relationships in leaves of $C_{3}$ plants. Oecologia 1989, 78, 9-19. [CrossRef]

38. Cornelissen, J.H.C.; Werger, M.J.A.; Castro-Diez, P.; Van Rheenen, J.W.A.; Rowland, A.P. Foliar nutrients in relation to growth, allocation and leaf traits in seedlings of a wide range of woody plant species and types. Oecologia 1997, 111, 460-469. [CrossRef] [PubMed]

39. Kattge, J.; Knorr, W.; Raddatz, T.; Wirth, C. Quantifying photosynthetic capacity and its relationship to leaf nitrogen content for global-scale terrestrial biosphere models. Glob. Chang. Biol. 2009, 15, 976-991. [CrossRef] 
40. Cui, X.; Yue, P.; Wu, W.; Gong, Y.; Li, K.; Misselbrook, T.; Goulding, K.; Liu, X. The growth and N retention of two annual desert plants varied under different nitrogen deposition rates. Front. Plant Sci. 2019, 10, 356. [CrossRef]

41. Niu, K.; He, J.; Lechowicz, M.J. Foliar phosphorus content predicts species relative abundance in P-limited Tibetan alpine meadows. Perspect. Plant Ecol. 2016, 22, 47-54. [CrossRef]

42. Dietze, M.C.; Sala, A.; Carbone, M.S.; Czimczik, C.I.; Mantooth, J.A.; Richardson, A.D.; Vargas, R. Nonstructural carbon in woody plants. Annu. Rev. Plant. Biol. 2014, 65, 667-687. [CrossRef] [PubMed]

43. Ma, S.; He, F.; Tian, D.; Zou, D.; Yan, Z.; Yang, Y.; Zhou, T.; Huang, K.; Shen, H.; Fang, J. Variations and determinants of carbon content in plants: A global synthesis. Biogeosciences 2018, 15, 693-702. [CrossRef]

44. Hedin, L.O. Global organization of terrestrial plant-nutrient interactions. Proc. Natl. Acad. Sci. USA 2004, 101, 10849-10850 [CrossRef] [PubMed]

45. Elser, J.J.; Dobberfuhl, D.R.; MacKay, N.A.; Schampel, J.H. Organism size, life history, and N: P stoichiometry: Toward a unified view of cellular and ecosystem processes. BioScience 1996, 46, 674-684. [CrossRef]

46. Elser, J.J.; Acharya, K.; Kyle, M.; Cotner, J.; Makino, W.; Markow, T.; Watts, T.; Hobbie, S.; Fagan, W.; Schade, J.; et al. Growth rate-Stoichiometry couplings in diverse biota. Ecol. Lett. 2003, 6, 936-943. [CrossRef]

47. Wright, I.J.; Reich, P.B.; Westoby, M. Strategy shifts in leaf physiology, structure and nutrient content between species of high-and low-rainfall and high-and low-nutrient habitats. Funct. Ecol. 2001, 15, 423-434. [CrossRef]

48. Fynn, R.W.S.; Morris, C.D.; Kirkman, K.P. Plant strategies and trait trade-offs influence trends in competitive ability along gradients of soil fertility and disturbance. J. Ecol. 2005, 93, 384-394. [CrossRef]

49. Stursova, M.; Crenshaw, C.L.; Sinsabaugh, R.L. Microbial responses to long-term N deposition in a semiarid grassland. Microb. Ecol. 2006, 51, 90-98. [CrossRef]

50. Zhou, X.; Zhang, Y.; Downing, A. Non-linear response of microbial activity across a gradient of nitrogen addition to a soil from the Gurbantunggut Desert, northwestern China. Soil. Biol. Biochem. 2012, 47, 67-77. [CrossRef]

51. Baskin, C.C.; Baskin, J.M. Seeds: Ecology, Biogeography and Evolution of Dormancy and Germination, 2nd ed.; Academic Press: San Diego, CA, USA, 2014; pp. 955-956.

52. Basto, S.; Thompson, K.; Phoenix, G.; Sloan, V.; Leake, J.; Rees, M. Long-term nitrogen deposition depletes grassland seed banks. Nat. Commun. 2015, 6, 6185. [CrossRef] [PubMed] 